\title{
Lactoferrin promotes hair growth in mice and increases dermal papilla cell proliferation through Erk/Akt and Wnt signaling pathways
}

\author{
Hsiu-Chin Huang ${ }^{1} \cdot$ Hsuan Lin ${ }^{1} \cdot$ Min-Chuan Huang ${ }^{2}$
}

Received: 5 October 2018 / Revised: 4 March 2019 / Accepted: 13 April 2019 / Published online: 20 April 2019

(c) The Author(s) 2019

\begin{abstract}
Hair loss affects men and women of all ages. Dermal papilla (DP) plays a crucial role in regulating the growth and cycling of hair follicles. Lactoferrin (LF) exhibits a wide range of biological functions, including antimicrobial activity and growth regulation. However, its effect on DP and its role in hair growth remain unknown. In this study, we found that bovine LF (bLF) promoted the proliferation of DP cells and enhanced the phosphorylation of Erk and Akt. The bLF-mediated proliferation was significantly blocked by the Erk phosphorylation inhibitor PD98059 or the Akt phosphorylation inhibitor LY294002. Moreover, biotin-labeled bLF could bind to DP cells, and the binding was independent of lipoprotein receptor-related protein 1, a known LF receptor. Importantly, bLF stimulated hair growth in both young and aged mice. Moreover, we also found that bLF significantly induced the expression of Wnt signaling-related proteins, including Wnt3a, Wnt7a, Lef1, and $\beta$-catenin. The bLF-mediated DP cell proliferation could be significantly reversed by the Wnt pathway inhibitor XAV939. Our findings suggest that bLF promotes hair growth in mice and stimulates proliferation of DP cells through Erk/Akt and Wnt signaling pathways. This study highlights a great potential of the use of bLF in developing drugs to treat hair loss.
\end{abstract}

Keywords Lactoferrin · Alopecia $\cdot$ Hair · Dermal papilla

\section{Introduction}

Although hair loss is not a lethal disease, it affects social and psychologic well-being. According to the previous study [32], androgenic alopecia (AGA) affects about $80 \%$ of Caucasian men and increases with age. Female pattern hair loss is estimated to occur in $32 \%$ of women in the ninth decade of life. Minoxidil and finasteride are the only two AGA treatments approved by the US Food and Drug Administration (FDA). Many new treatments have been introduced in recent years [36]. However, the effects of these treatments are not well characterized. In most cases, the results vary or present with unpredictable side effects. Most of them are trying to convert hair follicles from the telogen to anagen phase.

The adult hair follicle comprises three phases of hair cycle: the growth phase (anagen), the regression phase

Min-Chuan Huang

mchuang@ntu.edu.tw

1 Renorigin Innovation Institute Co. Ltd., Taipei, Taiwan

2 Graduate Institute of Anatomy and Cell Biology, College of Medicine, National Taiwan University, No. 1, Sec. 1, Ren'ai Road, Taipei 100, Taiwan (catagen), and the resting phase (telogen) [10]. Hair growth cycle is dependent on the interaction of epithelial and specialized mesenchymal cells called dermal papilla (DP), which are located at the base of the follicle. To stimulate the initiation of anagen, DP cells generate instructive signals to induce epithelial bulge cell proliferation [25]. A previous study [4] also indicated that DP cells play an important role in initiating anagen by inducing stem cells. Moreover, hair follicles with a normal keratinocyte compartment fail to generate new hair shafts if the density of DP cells is under the critical threshold.

Lactoferrin (LF; molecular weight, $\sim 80 \mathrm{kDa}$ ) is an ironbinding glycoprotein belonging to the transferrin family. LF can be found in many exocrine glands, pre-neoplastic and neoplastic lesions [34], and body fluids, including saliva, tears, semen, pancreatic fluids, bile, vaginal secretions, and milk. LF is a pleiotropic protein [21] which exerts effects on antimicrobial activity, immune system modulation, embryonic development, cell growth and differentiation, endothelial cell adhesion, myelopoiesis, cytokine and chemokine regulation, inflammatory response, and immunomodulatory activities [35]. However, its role on hair follicles has received little attention. 
The present study addresses the effects of bovine LF (bLF) on hair growth and the underlying mechanisms involved. The results suggest that bLF can act as a growth factor to stimulate DP cell proliferation and hair growth and highlight the potential of LF as a novel agent for alopecia treatment.

\section{Materials and methods}

\section{Cell culture}

DP cells were obtained from rat whisker follicle as previously described [1]. Briefly, 8-week Sprague-Dawley rats (BioLASCO, Taipei, Taiwan) were euthanized by $\mathrm{CO}_{2}$, and the whisker pads were removed from rats. The tissues were quickly washed in phosphate-buffered saline (PBS) and then transferred to Dulbecco's modified Eagle's medium (DMEM) (Gibco; Thermo Fisher Scientific, Waltham, MA, USA) supplemented with $10 \%$ fetal bovine serum (FBS) (Gibco), $100 \mathrm{U} / \mathrm{mL}$ penicillin, $100 \mu \mathrm{g} / \mathrm{mL}$ streptomycin, and $0.5 \mu \mathrm{g} / \mathrm{mL}$ fungizone (Gibco). After the removal of the adhering dermal tissues, 20 isolated follicles were transferred to fresh growth medium and cut into small pieces. Cells were incubated at $37^{\circ} \mathrm{C}$ in a humidified atmosphere containing $5 \% \mathrm{CO}_{2}$ in air. DP cells were obtained after 7 days. To confirm the identity of DP cells, the alkaline phosphatase (AP) activity was analyzed using Red-Color AP staining (System Biosciences, Mountain View, CA, USA). We have performed experiments using 5-8 passages of DP cells. LY294002 and PD98059 were purchased from Sigma. XAV939 was purchased from Abcam (Cambridge, UK).

\section{Cell proliferation assay}

Cells were seeded at a density of $2 \times 10^{3}$ cells in 96-well tissue culture plates. After $24 \mathrm{~h}$, the cells were treated with $20-100 \mu \mathrm{g} / \mathrm{mL}$ bLF and incubated for different time periods (1-5 days). After different culture times, cells were incubated for $4 \mathrm{~h}$ at $37^{\circ} \mathrm{C}$ with $0.5 \mathrm{mg} / \mathrm{mL}$ MTT, and then, $10 \%$ sodium dodecyl sulfate (SDS) containing $0.01 \mathrm{~N} \mathrm{HCl}$ was added to dissolve formazan crystals. Finally, the absorbance was measured at $570 \mathrm{~nm}$ and $630 \mathrm{~nm}$ using VersaMax ELISA microplate reader spectrophotometer (Molecular Devices, Silicon Valley, CA, USA).

\section{Western blot analysis}

Protein lysates of cells were prepared using NP40 lysis buffer. Then, $30 \mu \mathrm{g}$ of proteins was separated by $8 \%$ SDSPAGE and then transferred to polyvinylidene difluoride (PVDF) membranes. The membranes were incubated with blocking buffer and then incubated with the primary antibodies for pAkt (\#4060), Akt (\#4691), pErk1/2 (\#9101), Erk1/2 (\#9102) (Cell Signaling Technology Danvers, MA, USA), Wnt3a (GTX128101), Wnt7a (GTX128106), Lef1 (GTX129186) (GeneTex, Taiwan) and $\beta$-actin (SigmaAldrich, St Louis, MO, USA), followed by incubating with secondary antibodies peroxidase-AffiniPure goat anti-mouse (115-035-003) or anti-rabbit (111-035-144) antibody (Jackson ImmunoResearch Laboratories, West Grove, PA, USA).

\section{Biotinylation of LF and cell surface binding assay}

bLF was purchased from New Bellus Enterprise Co., Ltd (Tainan, Taiwan). Biotinylation of bLF was performed as previously described [28]. Briefly, bLF was incubated with biotin (Thermo Fisher Scientific) on ice for $2 \mathrm{~h}$. Unlabeled proteins were removed by dialysis against $1 \mathrm{~L}$ of $\mathrm{ddH}_{2} \mathrm{O}$ twice. The reaction of bLF binding to DP cells was performed according to a previous report [28]. Briefly, DP cells were seeded at a density of $1 \times 10^{4}$ cells in 96-well tissue culture plates and incubated with $0.1 \mu \mathrm{M}$ biotin-labeled bLF or biotin-labeled BSA in the presence or absence of 100-fold unlabeled $10-\mu \mathrm{M}$ bLF or BSA and recombinant receptorassociated protein (RAP) (Progen, Heidelberg, Germany) at $4{ }^{\circ} \mathrm{C}$. After $4 \mathrm{~h}$, the cells were washed and incubated for $1 \mathrm{~h}$ with HRP-conjugated avidin (BioGenex Fremont, CA, USA) at room temperature (RT). The biotin-avidin complex was detected with the $o$-phenylenediamine (OPD) substrate reagent from Sigma-Aldrich (P8787). Reactions were stopped with $3 \mathrm{~N} \mathrm{HCl}$ and read at $492 \mathrm{~nm}$ using an automated plate reader (molecular devices).

\section{Immunofluorescence microscopy}

DP cells were seeded at a density of $1 \times 10^{5}$ cells in 6-well tissue culture plates. After $24 \mathrm{~h}$, the cells were incubated with biotin-labeled bLF or BSA for $1 \mathrm{~h}$ and then fixed with $100 \%$ methanol. After $5 \mathrm{~min}$, the cells were washed and incubated with PBS containing 10\% FBS for 20 min. Then, the blocking buffer was removed, and streptavidin-FITC conjugate (Jackson ImmunoResearch Laboratories) was added; this was followed by incubation in the dark at RT for $1 \mathrm{~h}$, after which the cells were washed and observed under a fluorescence microscope.

\section{Hair growth in mice}

All animal experiments were approved by the Institutional Animal Care and Use Committee of the National Taiwan University College of Medicine, Taipei,Taiwan (IACUC: 20160283). To investigate the influence of bLF on hair growth, 2-month-old and 1-year-old female mice (C57BL/6) (BioLASCO) were anesthetized, and the dorsal hair were removed by a wax-rosin mixture as previously 
described [30]. After depilation for 1 day, bLF or $\mathrm{ddH}_{2} \mathrm{O}$ control was applied on the back twice daily for 7-12 days. Hair growth was quantified by analyzing the grey-scale of images of the dorsal skin using ImageQuant TL software and normalized to their levels at day $0 .{ }^{*} p<0.05$.

\section{Real-time reverse transcription polymerase chain reaction (RT-PCR) analysis}

Total RNA was extracted from DP cells using TRIzol ${ }^{\mathrm{TM}}$ Reagent (Invitrogen; Thermo Fisher Scientific), and cDNA was synthesized using reverse transcription kit (Applied Biosystems; Thermo Fisher Scientific). For real-time PCR, QuantStudio 3 Real-Time PCR System (Thermo Fisher Scientific) was used. Total reaction volume of $20 \mu \mathrm{L}$ contained $1-\mu \mathrm{L}$ cDNA, $500 \mathrm{nM}$ of each primer, and $10-\mu \mathrm{L}$ SensiFASTTM SYBR Lo-ROX Kit (Bioline, Taunton, MA, USA). Samples were analyzed in triplicate, and $\beta$-actin was used as an internal control to normalize the relative quantity of gene expression. For PCR, total volume of $50 \mu \mathrm{L}$ contained $1-\mu \mathrm{L}$ cDNA, $200 \mathrm{nM}$ of each primer, Dream Taq DNA Polymerase and Dream Taq buffer (Thermo Fisher Scientific) for 35 cycles. The following primer pairs were used: Wnt $3 a, 5^{\prime}$-AGTGCA AATGCCACGGACTA-3' (forward), 5'-TTGGGCTCG CAGAAGTTAGG-3' (reverse); Wnt7a, 5'-CAGAATGCC CGAACCCTCAT-3' (forward), 5'-TAGCCT GAGGGG CTGTCTTA-3' (reverse); $\beta$-catenin, 5'-CCATCACCA CGCTGCATAAT-3' (forward), 5'-GAGCAGACAGAC AGCACCTT-3' (reverse); Lefl, 5'-GGCATC CCTCAT CCAGCAAT-3' (forward), 5'-GTTGATAGCTGCGCT CTCCT-3' (reverse); Gsk3b, 5'-AGAACCACCTCCTTT GCGGA-3' (forward), 5'-GTGGTTACCTTGCTGCCA TCT-3' (reverse); $F z d 7,5^{\prime}$-GGTGGATGGTGACCTACT CA-3' (forward), 5'-GCTCGTAAAAGTAGCACGCC-3' (reverse); and $\beta$-actin, $5^{\prime}$-AAGATCCTGACCGA GCG
TGG-3' (forward), 5'-CCGCTCATTGCCGATAGTG-3' (reverse).

\section{Statistical analyses}

Data are presented as the mean values \pm standard deviation (SD) from at least three independent experiments. Student's $t$ tests were used to compare the differences between groups. One-way ANOVA followed by Tukey's post-hoc tests were used to compare the differences among multiple groups. Two-way ANOVA was used for the immunofluorescence assay. Statistical analyses were performed using GraphPad Prism 5 (GraphPad Software, USA). $p<0.05$ was considered statistically significant.

\section{Results}

\section{bLF increases cell proliferation in DP cells}

To investigate whether bLF could regulate cell proliferation, the MTT assay was performed. The results showed that $50 \mu \mathrm{g} / \mathrm{mL}$ of bLF significantly increased the growth rate of DP cells since day 3 (Fig. 1a), and the effect of different concentrations of bLF on DP cells at day 5 is shown (Fig. 1b). According to the results of Fig. 1a, the doubling times of DP cell proliferation for the bLF-treated and control groups were $\sim 32$ and $\sim 37 \mathrm{~h}$, respectively. These findings suggest that bLF increases DP cell proliferation.

\section{bLF increases phosphorylation of Erk and Akt in DP cells}

As it is well known that the Erk and Akt signaling pathways are involved in cell proliferation and differentiation, we analyzed the phosphorylation of Erk and Akt using Western blot analysis. We found that bLF was able to increase the phosphorylation levels of both Erk1/2 and Akt in DP cells
Fig. 1 bLF increases cell proliferation in DP cells. a DP cells were treated with $50 \mu \mathrm{g} / \mathrm{mL}$ bLF for 0-5 days. b Cell growth at different concentrations of bLF at day 5. Cell proliferation was analyzed by the MTT assay. Data are presented as the mean values \pm SD from three independent experiments. $* * * p<0.001$ (a)

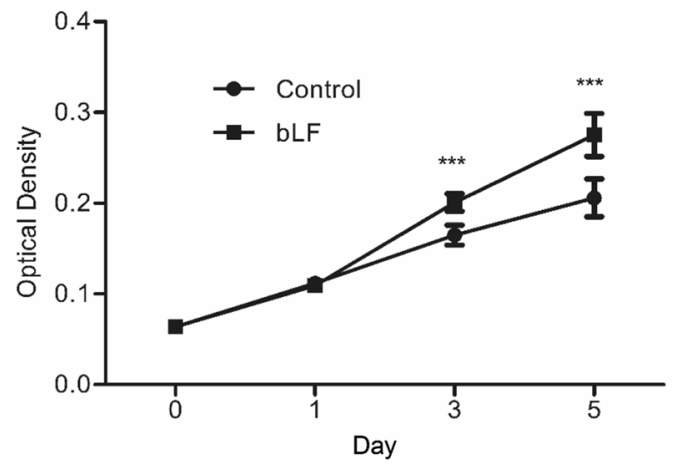

(b)

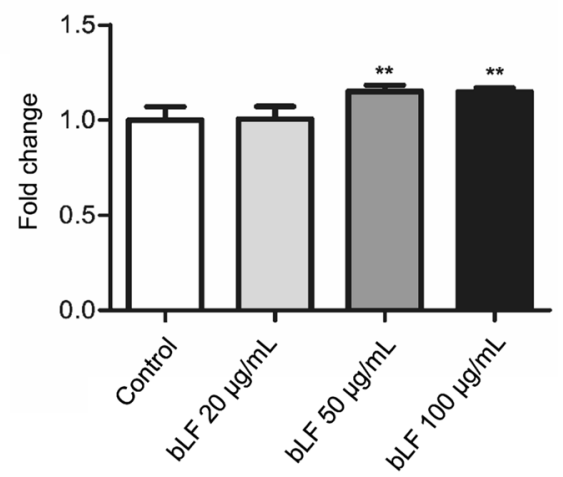


(a)

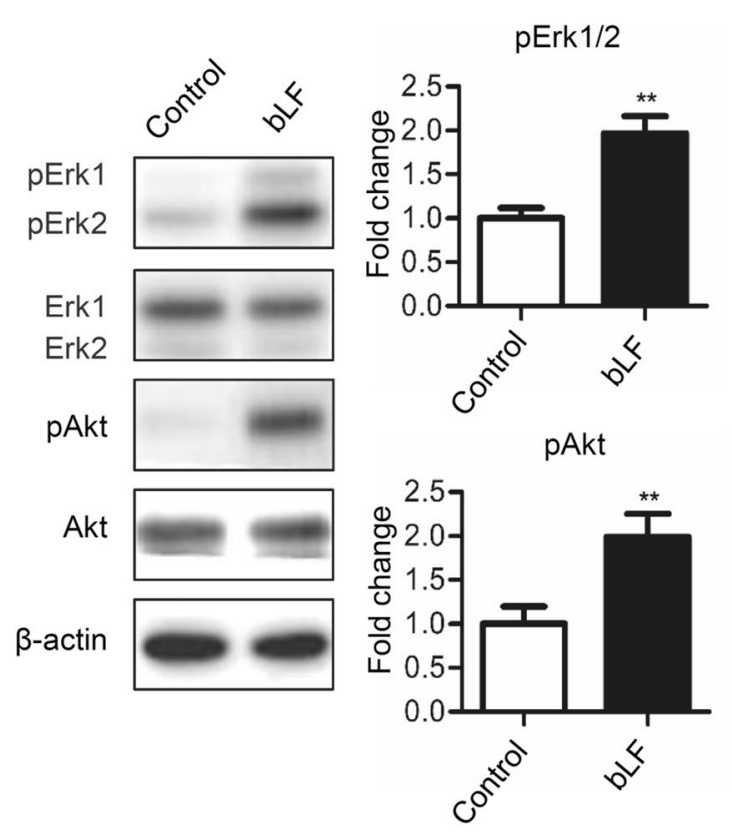

Fig. 2 bLF increases phosphorylation of Erk and Akt in DP cells. a DP cells were serum-starved for $1 \mathrm{~h}$ and subsequently treated with $50 \mu \mathrm{g} / \mathrm{mL}$ of bLF for $1 \mathrm{~h}$. Signals of phosphorylated proteins on Western blot analyses were quantified and normalized to their total protein levels. b DP cells treated with $50-\mu \mathrm{g} / \mathrm{mL}$ bLF and $5-\mu \mathrm{M}$

(Fig. 2a). To evaluate the role of Akt and Erk activation in bLF-mediated DP cell proliferation, we treated the cells with 5- $\mu$ M LY294002, an Akt phosphorylation inhibitor, and/or 5- $\mu \mathrm{M}$ PD98059, an Erk phosphorylation inhibitor. The MTT assay results showed that PD98059 or LY294002 decreased cell proliferation and also blocked the proliferative effect of bLF at day 3 (Fig. 2b). These findings indicate that bLF promotes cell proliferation through the activation of Erk and Akt signaling in DP cells.

\section{bLF binds to DP cells}

We examined whether bLF can bind to DP cells. The results showed that biotin-labeled bLF but not biotin-labeled BSA bound to DP cells (Fig. 3a). In the presence of a 100-fold molar excess of unlabeled bLF, the binding was reduced to the control level. By contrast, biotin-labeled bLF binding was not blocked by a 100-fold molar excess BSA. To further investigate and confirm the binding of biotin-labeled bLF was saturated, DP cells were treated with different concentrations of biotin-labeled bLF for $1 \mathrm{~h}$, and the cells were observed under a fluorescence microscope. The results showed that DP cells had strong signals of biotin-labeled bLF binding in the whole cell (Fig. 3b) and the binding of $0.5 \mu \mathrm{M}$ bLF reached to the plateau. So the saturated

(b)

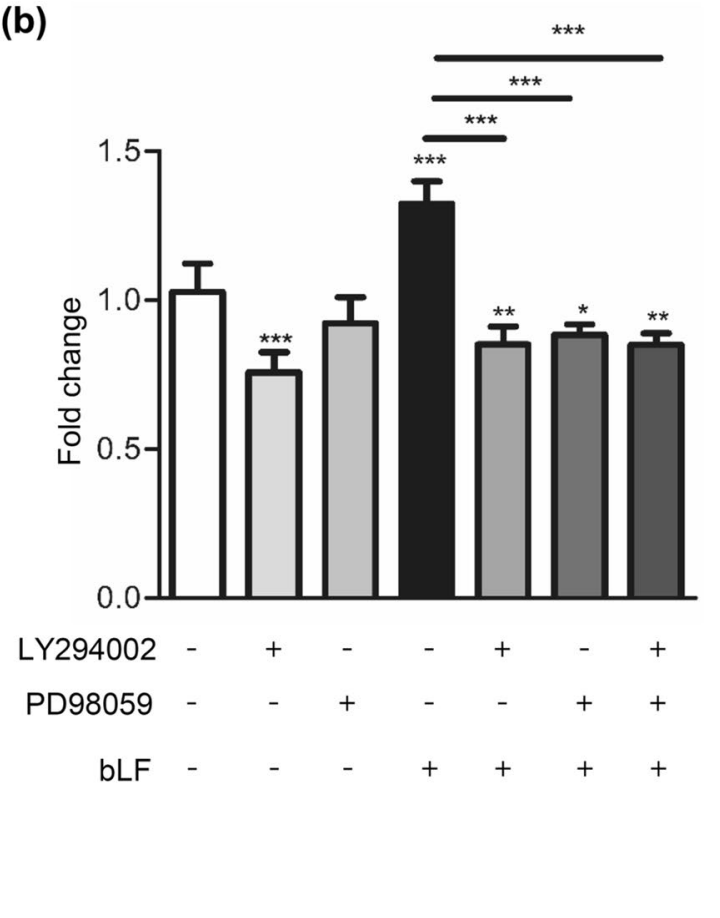

LY294002, 5- $\mu$ M PD98059, or a combined treatment of LY294002 and PD 98059 for 3 days. Cell proliferation was analyzed by the MTT assay. Data are presented as the mean values \pm SD from three independent experiments. $* p<0.05$; $* * p<0.01 ; * * * p<0.001$

concentration of biotin-labeled bLF in DP cells is $\sim 0.5 \mu \mathrm{M}$. Conversely, biotin-BSA also had relatively weak signals. These findings indicate that bLF specifically binds to DP cells.

\section{RAP does not compete with bLF for binding to DP cells}

Low-density lipoprotein receptor-related protein 1 (LRP1), one of LF receptors in mammalian cells, is present in human skin keratinocytes and fibroblasts [33]. A previous study indicated that DP cells from wild-type anagen follicles homogeneously express LRP1 in culture [6]. We also examined whether LRP1 can express in rat DP cells. The results of RT-PCR showed that DP cells expressed high levels of LRP1 mRNA (Fig. 4a). To investigate whether LRP1 is involved in the binding of bLF to DP cells, the cells were treated with biotin-labeled bLF together with RAP. RAP is a high-affinity ligand for LRP used as a universal competitor for LRP ligands [3]. DP cells were incubated with biotinlabeled bLF in the presence of increasing concentrations of RAP (0.1-0.4 $\mu \mathrm{M})$. However, our data showed that RAP, a protein that efficiently inhibits LF binding to LRP1, did not inhibit biotin-labeled bLF to DP cells (Fig. 4b), suggesting that bLF does not bind to LRP1 on DP cells. It has been 
(a)

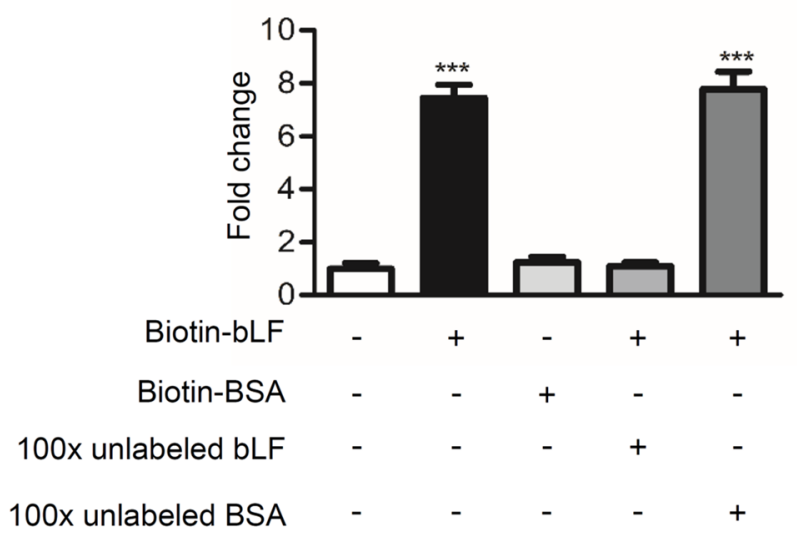

(b)
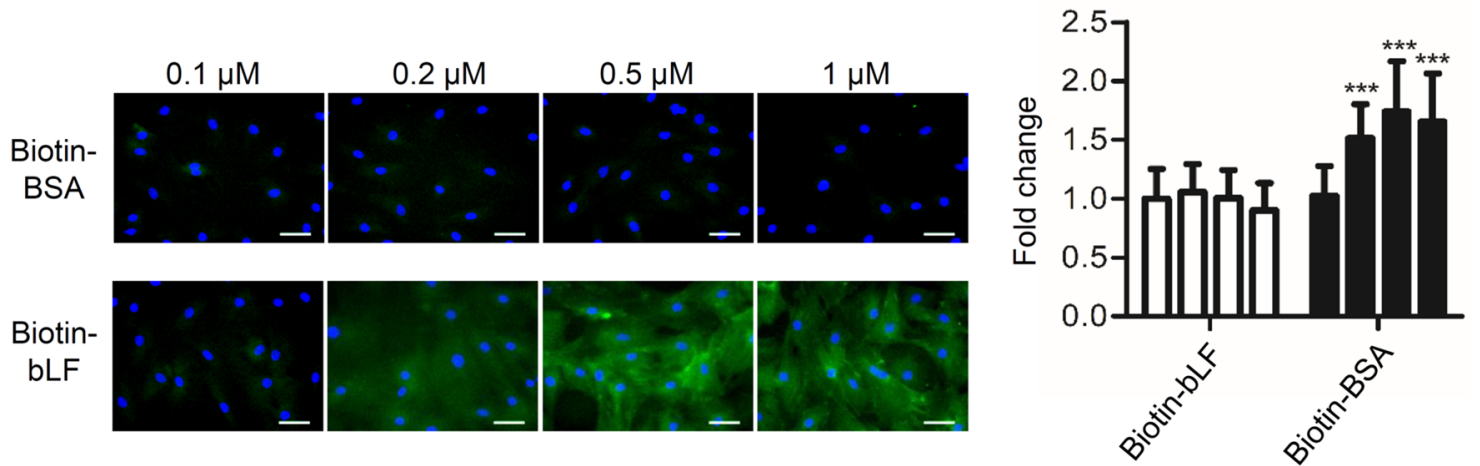

Fig. 3 Binding of bLF to DP cells. a DP cells were treated with $0.1-\mu \mathrm{M}$ biotin-labeled bLF or biotin-labeled BSA in the presence of 100 -fold molar excess of unlabeled bLF or BSA for $4 \mathrm{~h}$ at $4{ }^{\circ} \mathrm{C}$. The binding of biotin-labeled bLF to DP cells was detected by incubating them with HRP-conjugated avidin, followed by adding the OPD substrate reagent and measuring the absorbance at $492 \mathrm{~nm}$. b Following methanol fixation and permeabilization, cells treated with biotinlabeled bLF or biotin-labeled BSA were stained for streptavidin-FITC

reported that intelectin is a LF receptor in the small intestine [31]. Our data showed that intelectin was not expressed in rat DP cells (Fig. 4a). These observations suggest that LRP1 is not involved in the specific binding of bLF to DP cells.

\section{bLF increases hair growth in C57BL/6 mice}

To assess the effect of bLF on hair loss in vivo, hairs of mice at 2 months and 1 year of age were synchronized by depilation. bLF was applied on the back twice daily for 7-12 days. In young mice, hair growth of the back skin was faster in bLF-treated mice than in control mice (Fig. 5a). Moreover, histological analysis of the back skin showed a significantly increased number of hair follicles in bLF-treated mice (Fig. 5b). In aged mice, we also found that bLF could significantly promote hair growth (Fig. 5c). These findings suggest that bLF increases hair growth in both young and aged C57BL/6 mice.
$\mathrm{Ab}$ (green), and their nuclei were stained with DAPI (blue). Fluorescent microscopy showing DP cells treated with $0.1-1 \mu \mathrm{M}$ of biotinlabeled BSA and biotin-labeled bLF for $1 \mathrm{~h}$. The fluorescent levels of cells bound by biotin-bLF were quantified using AxioVision Software and normalized to the levels of biotin-BSA control. Scale bars, $50 \mu \mathrm{m}$. Data are presented as the mean values \pm SD from three independent experiments. $* * * p<0.001$

\section{bLF increases Wnt signaling-related genes and proteins in DP cells}

The Wnt pathway plays an essential role in hair follicle induction [29]. Therefore, we analyzed whether Wnt signaling-related genes were induced by bLF. DP cells were treated by bLF or minoxidil. Minoxidil is the first and so far the only FDA-approved topical product for the treatment of AGA [37]. The results of real-time RT-PCR indicated that bLF significantly increased the mRNA levels of $W n t 3 a$, Wnt7a, and Lefl, but not of $\beta$-catenin, Fzd7, and $G s k 3 b$ (Fig. 6). However, minoxidil could only increase the Lefl expression. Our results suggest that bLF regulates Wnt signaling pathways which are different from those modulated by minoxidil. We further analyzed the effect of bLF on the expression of the Wnt pathway-related proteins and the effect of the Wnt signaling inhibitor XAV939 on cell proliferation. XAV939 inhibits Wnt signaling by stimulating 
(a)

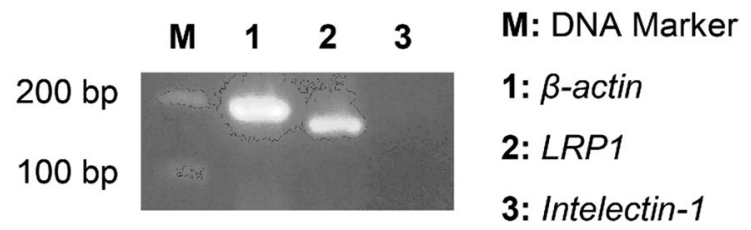

(b)

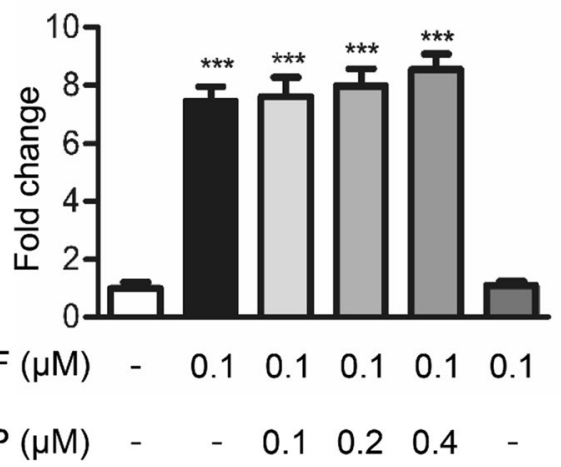

Unlabeled bLF $(\mu \mathrm{M}) \quad-\quad-\quad-\quad \ldots \quad-10$

Fig. 4 RAP does not compete with bLF for binding to DP cells. a The RT-PCR products of $\beta$-actin (lanes 1), LRP1 (lanes 2) and intelectin-1 (lane 3) were separated by an agarose gel. Intelectin-1 is a lactoferrin receptor expressed by the small intestine. b DP cells were plated onto 96-well tissue culture plates $\left(1 \times 10^{4}\right.$ cells/well $)$ and incubated with biotin-labeled bLF or biotin-labeled BSA in the presence of the indicated concentrations of RAP $(0.1-0.4 \mu \mathrm{M})$ for $4 \mathrm{~h}$ at $4{ }^{\circ} \mathrm{C}$. The binding of biotin-labeled bLF to DP cells was detected by incubation with HRP-conjugated avidin, which was followed by adding the OPD substrate reagent and measuring the absorbance at $492 \mathrm{~nm}$. Data are presented as the mean values \pm SD from three independent experiments. $* * * p<0.001$

$\beta$-catenin degradation. Western blot analysis showed that bLF increased protein levels of Wnt3a, Wnt7a, $\beta$-catenin, and Lef1 for both 48-h and 72-h treatments (Fig. 7a). The bLF-induced increase in cell proliferation could be significantly reversed by XAV939 (Fig. 7b). These results suggest Wnt signaling pathways are involved in bLF-induced proliferation of DP cells.

\section{Discussion}

LF exerts an effect on cell growth and differentiation [23]. In this study, we found that bLF promoted cell proliferation in DP cells and hair growth in mice. bLF increased Erk and Akt signaling independent of LRP1 receptors in DP cells. Moreover, bLF significantly induced the expression of Wnt signaling-related genes. Therefore, we propose that bLF stimulates cell proliferation in DP cells and hair growth in mice through Erk/Akt and Wnt pathways.
DP cell proliferation is important for the morphogenesis and growth of the hair follicles [26]. Erk and Akt signaling pathways are the two major controllers of cell proliferation. The Erk signaling pathway plays key roles in cell proliferation of many cells [39], including DP cells [18, 27]. Akt plays a critical role in mediating survival signals [5]. Moreover, it was reported that the Akt pathway is also involved in regulating the survival of DP cells [9]. Consistently, we found that bLF increases the growth of DP cells and the phosphorylation of Erk and Akt. Moreover, the Erk inhibitor PD98059 and the Akt inhibitor LY294002 significantly blocked bLF-induced proliferative effect in DP cells. Therefore, we propose that bLF is at least partly responsible for promoting the cell proliferation in DP cells by upregulating the Erk and Akt pathways.

LF exerts multiple functions by either binding to the membrane receptors to induce signal transduction pathways or entering the target cells via endocytosis [38]. Human neoplastic cell lines also reportedly have specific LF-binding sites, and a receptor-mediated endocytosis could be supposed [13]. Recent studies suggest that LRP1 functions as both an endocytic receptor and a signaling receptor [11, 19]. LF-induced proliferation and Erk signaling in osteoblastic cells were abrogated by RAP [8], which potently inhibits the binding of ligands to both LRP1 and LRP2 [7]. In our study, bLF can bind to DP cells and can be endocytosed. However, RAP cannot inhibit the binding of bLF to DP cells. These results suggest that LRP1 is not involved in bLF-induced cell proliferation. Other receptors that mediate endocytosis and enhance cell proliferation may exist. Therefore, to understand the complicated process of bLF-induced cell proliferation, it will be of great interest to further investigate the receptor responsible for bLF-mediated cell proliferation.

Hair loss, also known as alopecia, occurs in most people at some time in their life. Thus, it is very important to develop new therapeutic agents to stop hair loss and enhance hair growth. LF is a native and multifunctional glycoprotein in mammal milk which is known to exhibit a wide range of biological activities [22]. According to the previous study, the follicular penetration route may be especially relevant for large molecular weight (MW) molecules [17]. The higher MW dextrans (10-kDa MW) were confined to the follicular structures immediately surrounding the hair shaft [20]. Another paper showed that the FITC-labeled pollen proteins (10-100 kDa) were detected in the dermal tissue around the hair follicle [14]. These results suggest that large molecules could pass through the skin via hair follicles. Therefore, it is likely that lactoferrin can enter the bottom of hair follicles and then induce DP cell proliferation. In this study, the topical use of bLF significantly promoted hair induction in C57BL/6 mice, suggesting that bLF induces hair growth and has great potential for development of anti-alopecia drugs. For clinical applications, native bLF was rapidly degraded 
(a)

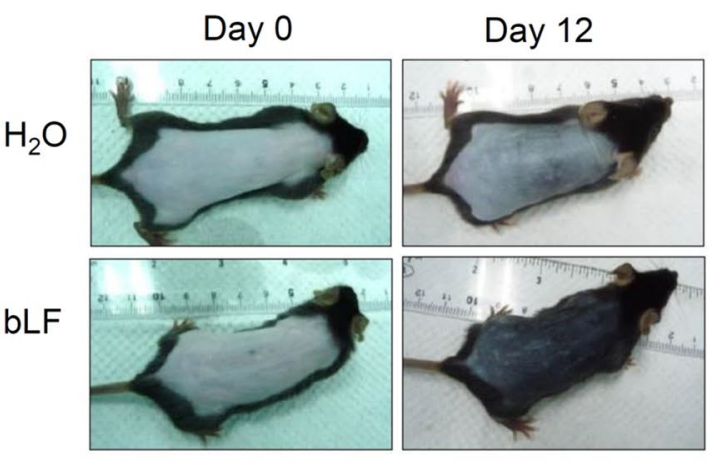

(b)

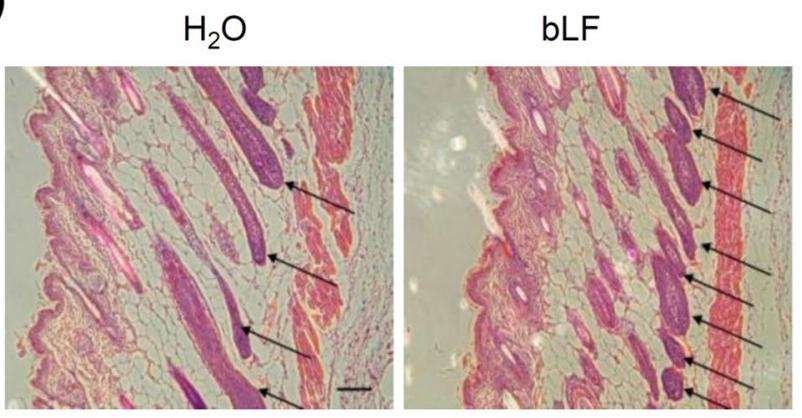

(c)

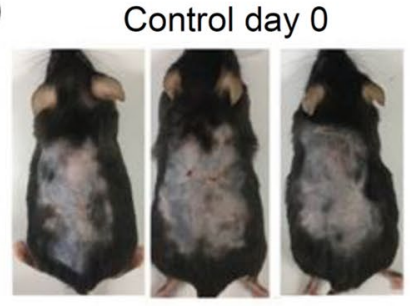

Control day 7

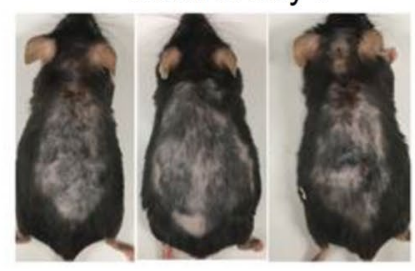

bLF day 0

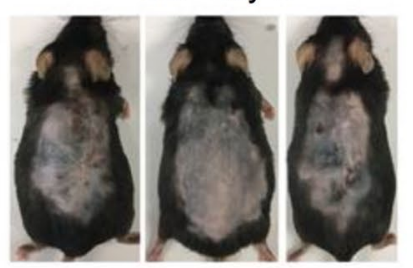

bLF day 7

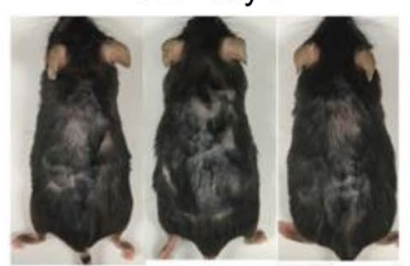

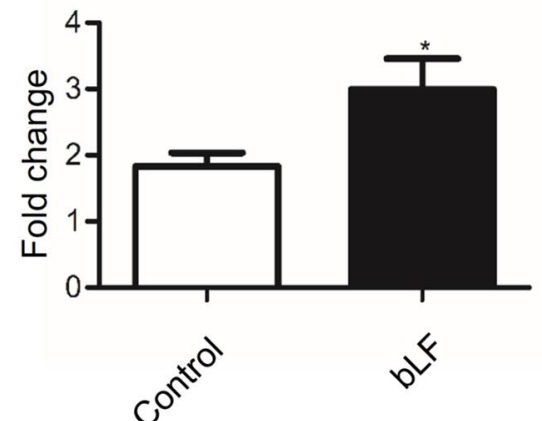

Fig. 5 bLF increases hair growth in both young and aged mice. a Young mice treated with $200-\mathrm{mg} / \mathrm{mL}$ bLF or $\mathrm{ddH}_{2} \mathrm{O}$. b Hemotoxylin and eosin staining of the back skin from the young mice. Longitudinal sections of hair follicles (arrows). Scale bar $=200 \mu \mathrm{m}$. c Aged mice treated with $40-\mathrm{mg} / \mathrm{mL}$ bLF or $\mathrm{ddH}_{2} \mathrm{O}$ control for 7 days. Hair growth was quantified using ImageQuant TL software and normalized to their levels at day $0 .{ }^{*} p<0.05$

the anagen state. Conversely, our data showed that minoxidil increased the expression of Lefl but not of Wnt3a and $W n t 7 a$. We also found that bLF increased the expression of the Wnt pathway-related proteins, namely Wnt3a, Wnt7a, $\beta$-catenin, and Lef1, and that the Wnt pathway inhibitor XAV939 significantly reversed the bLF-induced DP cell proliferation. These results suggest that Wnt signaling pathways are also involved in the bLF-mediated hair growth and that bLF and minoxidil induce hair growth by modulating different factors.

Taken together (Fig. 8), bLF could induce hair growth in young and aged mice. Mechanistically, bLF stimulates the proliferation of DP cells via Erk/Akt and Wnt signaling pathways, which are independent of LRP1. To our knowledge, we are the first to report bLF as a stimulator of hair growth. Our findings show a great potential of the use of bLF in developing agents to treat alopecia in the future. In the future studies, we will further study the effect of bLF on the stem cell niche or bLF on the proliferation of dermal papilla cells in vivo. 
Wnt3a
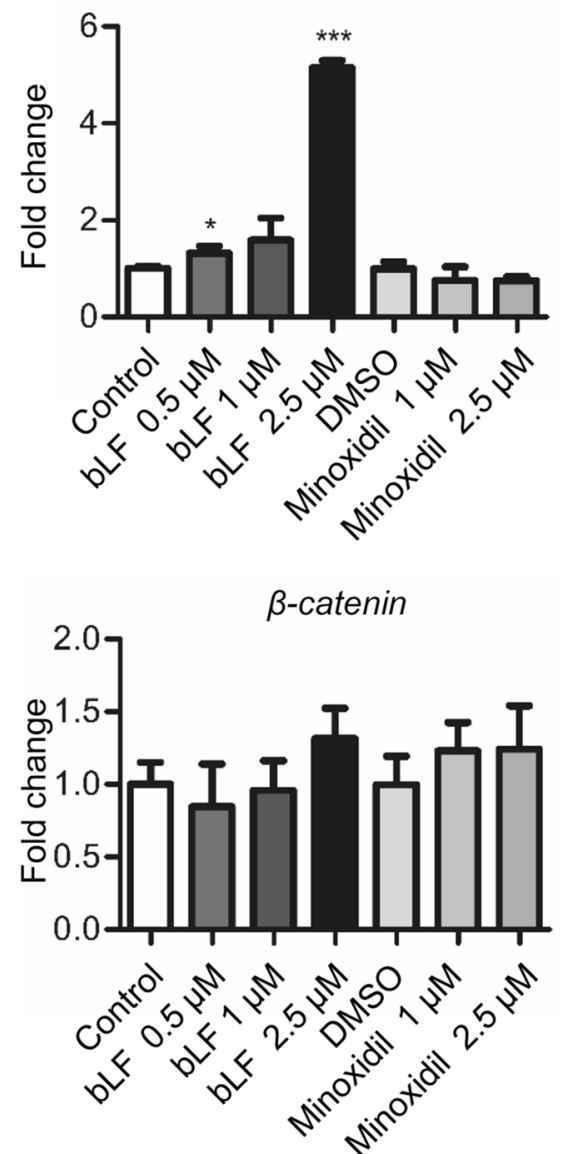

Wnt7a
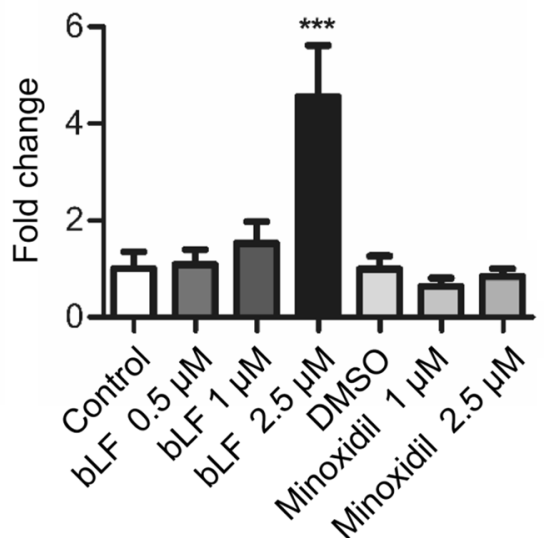

Gsk3b

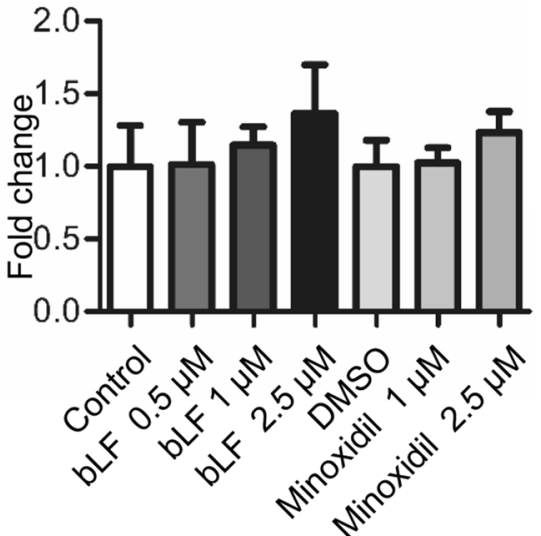

Lef1

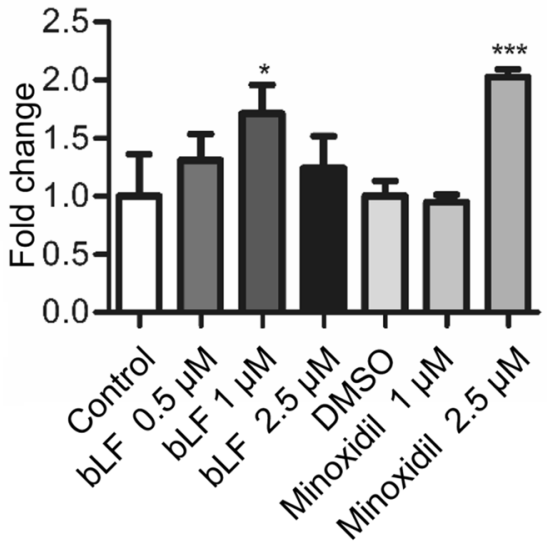

Fzd7

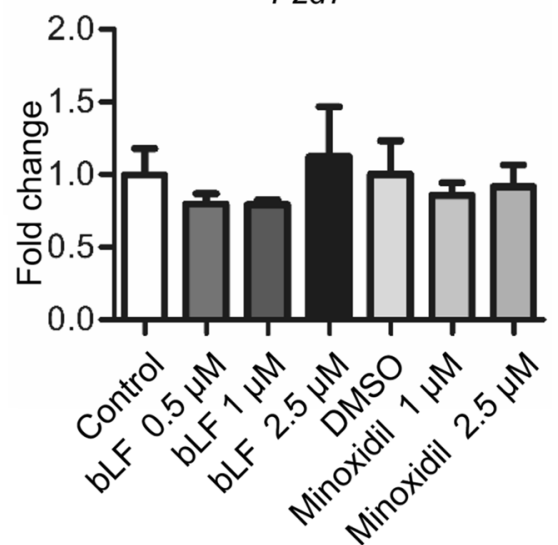

Fig. 6 bLF increases the expression of Wnt signaling-related genes in DP cells. The mRNA expression levels of Wnt3a, Wnt7a, and Lef1 in DP cells treated with $0.5-2.5 \mu \mathrm{M}$ of bLF or $1-2.5 \mu \mathrm{M}$ of minoxi- dil was analyzed by real-time RT-PCR. Data are presented as the mean values $\pm \mathrm{SD}$ from three independent experiments. $* p<0.05$; $* * * p<0.001$ (a)

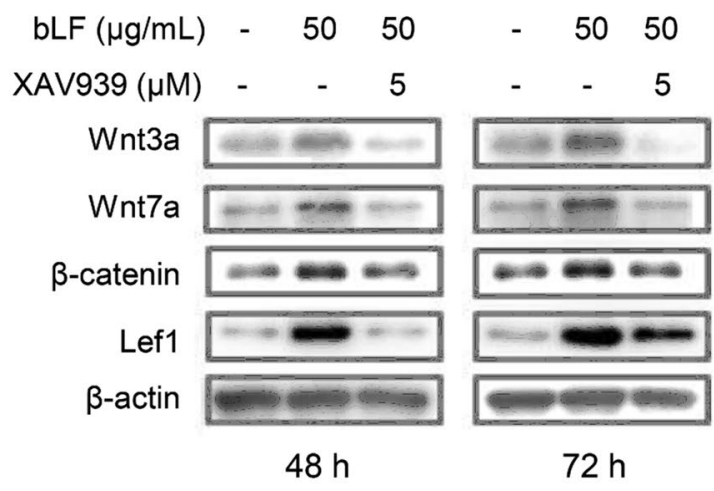

Fig. 7 bLF increases the Wnt pathway-related proteins in DP cells. a DP cells were treated with $50 \mu \mathrm{g} / \mathrm{mL}$ of bLF and/or 5- $\mu \mathrm{M}$ XAV939 for $48 \mathrm{~h}$ (left) or $72 \mathrm{~h}$ (right). Signals of proteins on Western blots were quantified and normalized to their total protein levels. b Cell (b)

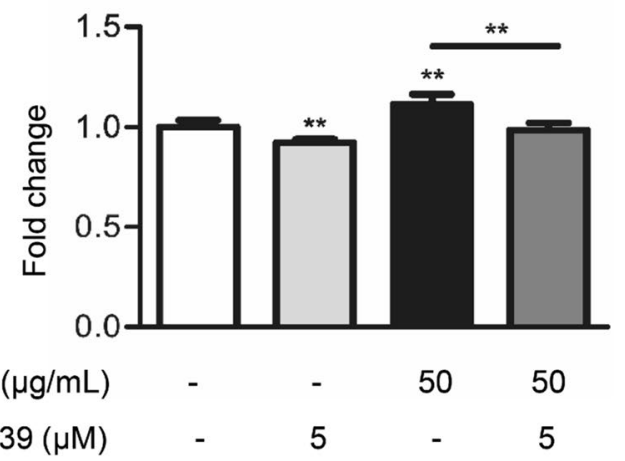

viability of DP cells treated with $50-\mu \mathrm{g} / \mathrm{mL}$ bLF and/or $5-\mu \mathrm{M}$ XAV939 for 5 days. Cell viability was analyzed using the MTT assay. Data are presented as the mean values \pm SD from three independent experiments. ${ }^{*} p<0.05 ; * * p<0.01$ 


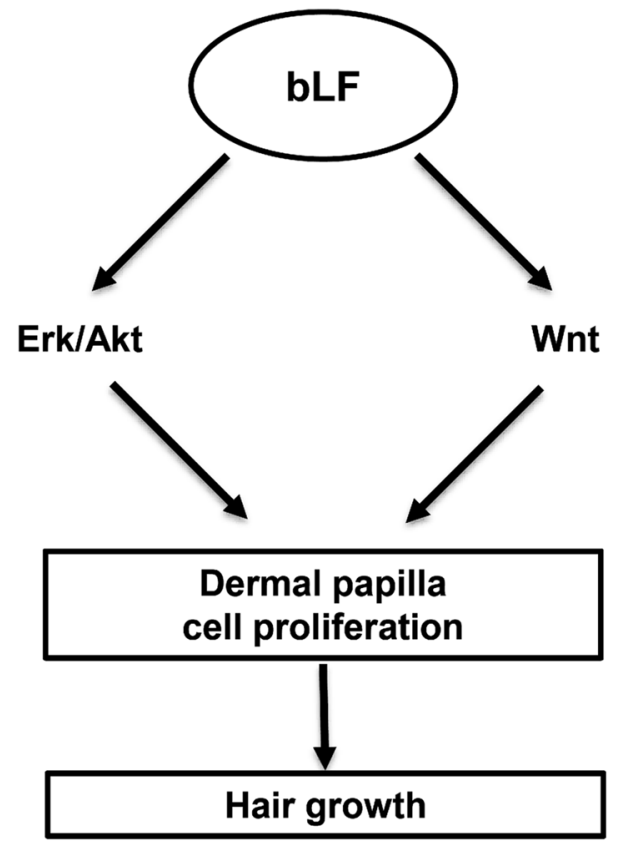

Fig. 8 A schematic depicting the potential mechanisms involved in bLF-induced hair growth. $b L F$ bovine lactoferrin, Erk extracellular signal-regulated kinase, Akt protein kinase $\mathrm{B}$

Acknowledgements This study was supported by grants from the National Taiwan University 106M118 and 107M119.

\section{Compliance with ethical standards}

Conflict of interest The authors have no conflict of interest to declare.

Ethical approval All animal experiments were approved by the Institutional Animal Care and Use Committee of the National Taiwan University College of Medicine, Taipei, Taiwan.

Open Access This article is distributed under the terms of the Creative Commons Attribution 4.0 International License (http://creativeco mmons.org/licenses/by/4.0/), which permits unrestricted use, distribution, and reproduction in any medium, provided you give appropriate credit to the original author(s) and the source, provide a link to the Creative Commons license, and indicate if changes were made.

\section{References}

1. Almond-Roesler B, Schon M, Schon MP, Blume-Peytavi U, Sommer C, Loster K, Orfanos CE (1997) Cultured dermal papilla cells of the rat vibrissa follicle. Proliferative activity, adhesion properties and reorganization of the extracellular matrix in vitro. Arch Dermatol Res 289:698-704

2. Behrens J, von Kries JP, Kuhl M, Bruhn L, Wedlich D, Grosschedl R, Birchmeier W (1996) Functional interaction of beta-catenin with the transcription factor LEF-1. Nature 382:638-642

3. Bu G, Marzolo MP (2000) Role of rap in the biogenesis of lipoprotein receptors. Trends Cardiovasc Med 10:148-155
4. Chi W, Wu E, Morgan BA (2013) Dermal papilla cell number specifies hair size, shape and cycling and its reduction causes follicular decline. Development 140:1676-1683

5. Datta SR, Brunet A, Greenberg ME (1999) Cellular survival: a play in three Akts. Genes Dev 13:2905-2927

6. Feutz AC, Barrandon Y, Monard D (2008) Control of thrombin signaling through $\mathrm{PI} 3 \mathrm{~K}$ is a mechanism underlying plasticity between hair follicle dermal sheath and papilla cells. J Cell Sci 121:1435-1443

7. Gliemann J (1998) Receptors of the low density lipoprotein (LDL) receptor family in man. Multiple functions of the large family members via interaction with complex ligands. Biol Chem 379:951-964

8. Grey A, Banovic T, Zhu Q, Watson M, Callon K, Palmano K, Ross J, Naot D, Reid IR, Cornish J (2004) The low-density lipoprotein receptor-related protein 1 is a mitogenic receptor for lactoferrin in osteoblastic cells. Mol Endocrinol 18:2268-2278

9. Han JH, Kwon OS, Chung JH, Cho KH, Eun HC, Kim KH (2004) Effect of minoxidil on proliferation and apoptosis in dermal papilla cells of human hair follicle. J Dermatol Sci 34:91-98

10. Hardy MH (1992) The secret life of the hair follicle. Trends Genet 8:55-61

11. Herz J, Gotthardt M, Willnow TE (2000) Cellular signalling by lipoprotein receptors. Curr Opin Lipidol 11:161-166

12. Huelsken J, Vogel R, Erdmann B, Cotsarelis G, Birchmeier W (2001) beta-Catenin controls hair follicle morphogenesis and stem cell differentiation in the skin. Cell 105:533-545

13. Ieni A, Barresi V, Grosso M, Rosa MA, Tuccari G (2009) Lactoferrin immuno-expression in human normal and neoplastic bone tissue. J Bone Miner Metab 27:364-371

14. Jacobi U, Engel K, Patzelt A, Worm M, Sterry W, Lademann J (2007) Penetration of pollen proteins into the skin. Skin Pharmacol Physiol 20:297-304

15. Kim HJ, Shin CH, Kim CW (2009) Stabilization of glycoprotein liquid formulation using arginine: a study with lactoferrin as a model protein. Biosci Biotechnol Biochem 73:61-66

16. Kishimoto J, Burgeson RE, Morgan BA (2000) Wnt signaling maintains the hair-inducing activity of the dermal papilla. Genes Dev 14:1181-1185

17. Knorr F, Lademann J, Patzelt A, Sterry W, Blume-Peytavi U, Vogt A (2009) Follicular transport route-research progress and future perspectives. Eur J Pharm Biopharm 71:173-180

18. Li W, Man XY, Li CM, Chen JQ, Zhou J, Cai SQ, Lu ZF, Zheng M (2012) VEGF induces proliferation of human hair follicle dermal papilla cells through VEGFR-2-mediated activation of ERK. Exp Cell Res 318:1633-1640

19. Li Y, Cam J, Bu G (2001) Low-density lipoprotein receptor family: endocytosis and signal transduction. Mol Neurobiol 23:53-67

20. Lieb LM, Liimatta AP, Bryan RN, Brown BD, Krueger GG (1997) Description of the intrafollicular delivery of large molecular weight molecules to follicles of human scalp skin in vitro. J Pharm Sci 86:1022-1029

21. Mayeur S, Spahis S, Pouliot Y, Levy E (2016) Lactoferrin, a pleiotropic protein in health and disease. Antioxid Redox Signal 24:813-836

22. Mulder AM, Connellan PA, Oliver CJ, Morris CA, Stevenson LM (2008) Bovine lactoferrin supplementation supports immune and antioxidant status in healthy human males. Nutr Res 28:583-589

23. Naot D, Grey A, Reid IR, Cornish J (2005) Lactoferrin-a novel bone growth factor. Clin Med Res 3:93-101

24. Nojima Y, Suzuki Y, Yoshida K, Abe F, Shiga T, Takeuchi T, Sugiyama A, Shimizu H, Sato A (2009) Lactoferrin conjugated with 40-kDa branched poly(ethylene glycol) has an improved circulating half-life. Pharm Res 26:2125-2132

25. Rahmani W, Abbasi S, Hagner A, Raharjo E, Kumar R, Hotta A, Magness S, Metzger D, Biernaskie J (2014) Hair follicle dermal 
stem cells regenerate the dermal sheath, repopulate the dermal papilla, and modulate hair type. Dev Cell 31:543-558

26. Rajendran RL, Gangadaran P, Bak SS, Oh JM, Kalimuthu S, Lee HW, Baek SH, Zhu L, Sung YK, Jeong SY, Lee SW, Lee J, Ahn BC (2017) Extracellular vesicles derived from MSCs activates dermal papilla cell in vitro and promotes hair follicle conversion from telogen to anagen in mice. Sci Rep 7:15560

27. Rastegar H, Ahmadi Ashtiani H, Aghaei M, Ehsani A, Barikbin B (2013) Combination of herbal extracts and platelet-rich plasma induced dermal papilla cell proliferation: involvement of ERK and Akt pathways. J Cosmet Dermatol 12:116-122

28. Rejman JJ, Turner JD, Oliver SP (1994) Characterization of lactoferrin binding to the MAC-T bovine mammary epithelial cell line using a biotin-avidin technique. Int J Biochem 26:201-206

29. Rishikaysh P, Dev K, Diaz D, Qureshi WM, Filip S, Mokry J (2014) Signaling involved in hair follicle morphogenesis and development. Int J Mol Sci 15:1647-1670

30. Stenn KS, Paus R, Dutton T, Sarba B (1993) Glucocorticoid effect on hair growth initiation: a reconsideration. Skin Pharmacol 6:125-134

31. Suzuki YA, Lopez V, Lonnerdal B (2005) Mammalian lactoferrin receptors: structure and function. Cell Mol Life Sci 62:2560-2575

32. Talavera-Adame D, Newman D, Newman N (2017) Conventional and novel stem cell based therapies for androgenic alopecia. Stem Cells Cloning 10:11-19

33. Tang L, Wu JJ, Ma Q, Cui T, Andreopoulos FM, Gil J, Valdes J, Davis SC, Li J (2010) Human lactoferrin stimulates skin keratinocyte function and wound re-epithelialization. Br J Dermatol 163:38-47

34. Tuccari G, Barresi G (2011) Lactoferrin in human tumours: immunohistochemical investigations during more than 25 years. Biometals 24:775-784

35. Tuccari G, Giuffre G, Crisafulli C, Barresi G (1998) Immunohistochemical demonstration of lactoferrin in human neoplastic tissues. Adv Exp Med Biol 443:337-340

36. Vano-Galvan S, Camacho F (2017) New treatments for hair loss. Actas Dermosifiliogr 108:221-228

37. Varothai S, Bergfeld WF (2014) Androgenetic alopecia: an evidence-based treatment update. Am J Clin Dermatol 15:217-230

38. Zhang W, Guo H, Jing H, Li Y, Wang X, Zhang H, Jiang L, Ren F (2014) Lactoferrin stimulates osteoblast differentiation through PKA and p38 pathways independent of lactoferrin's receptor LRP1. J Bone Miner Res 29:1232-1243

39. Zhang W, Liu HT (2002) MAPK signal pathways in the regulation of cell proliferation in mammalian cells. Cell Res 12:9-18

Publisher's Note Springer Nature remains neutral with regard to jurisdictional claims in published maps and institutional affiliations. 